\title{
Posttraumatic stress disorder and sleep quality among urban firefighters in Thailand
}

This article was published in the following Dove Press journal:

Nature and Science of Sleep

\author{
Chinchuta Khumtong ${ }^{1,2}$ \\ Nutta Taneepanichskul' \\ 'College of Public Health Sciences, \\ Chulalongkorn University, Bangkok, \\ Thailand; ${ }^{2}$ Faculty of Science and \\ Technology, Valaya Alongkorn Rajabhat \\ University, Phathum Thani, Thailand
}

\begin{abstract}
Background: Urban firefighters are at risk of posttraumatic stress disorder (PTSD) because of their occupational exposure to trauma events. Little is known, however, about the effects of exposure to trauma events on sleep quality among firefighters in Thailand.

Purpose: The objective of this study was to find an assocaition between PTSD and sleep quality among firefighters.
\end{abstract}

Methods: A cross-sectional study was conducted among active male firefighters in Bangkok. Participants completed the Posttraumatic Stress Disorder Checklist - Civilian Version (PCL-C-THAI) and the Pittsburgh Sleep Quality Index (PSQI-THAI) questionnaires. Multivariable logistic regression models were performed to estimate adjusted odds ratio (AOR) and 95\% confidence intervals (95\% CI).

Results: A total of 1215 firefighters participated, of which $78(6.4 \%)$ met the suggested PCL cut-point criteria for civilians (PCL-C scores $>44)$. In addition, 596 (49.1\%) had poor sleep quality (PSQI $>5$ ). PTSD firefighters had increased 6.49 fold odds of poorer sleep quality (AOR $=6.49,95 \%$ CI 3.13-13.44).

Conclusion: Firefighters with PTSD had a significantly higher probability of experiencing poor sleep quality than those without. In response, a psychological health intervention may be needed to enhance the firefighters' health.

Keywords: urban firefighter, posttraumatic stress disorder, PTSD, Posttraumatic Stress Disorder Checklist - Civilian Version, sleep quality, Thailand

\section{Introduction}

Firefighting is one of the most challenging, dangerous and stressful professions. In their working environment, firefighters are exposed to physical and psychological stresses. ${ }^{1}$ Posttraumatic stress disorder (PTSD) is a mental disorder included in the Diagnostic and Statistical Manual of Mental Disorders (fifth edition) under the trauma- and stressorrelated disorders category. ${ }^{2}$ PTSD can develop after exposure to death, threatened death and actual or threatened serious injury ${ }^{3}$ and is linked to several health hazards, for instance, cardiovascular disease, ${ }^{4}$ fibromyalgia, ${ }^{5}$ depression and suicide. ${ }^{6}$ In addition, a significant association between PTSD and poor sleep quality has been found. ${ }^{7}$

In the general population, the prevalence of PTSD ranges from $2.3 \%$ to $8.8 \%{ }^{8,9}$ In contrast, the prevalence among firefighters is higher than the general population. It was reported that $15.5 \%$ of American firefighters may have developed PTSD after exposure to the trauma in $9 / 11 .{ }^{10}$ In addition, $16-22 \%$ of retired male firefighters who worked at ground zero in 9/11 were diagnosed with PTSD using the Posttraumatic Stress Disorder Checklist - Civilian Version (PCL-C). ${ }^{11}$ In Thailand, no report has reviewed the epidemiological data focusing on prevalence of lifetime PTSD among general and
Correspondence: Nutta Taneepanichskul College of Public Health Sciences, Chulalongkorn University, Institute Building 2-3, Phyathai Road, Pathumwan, Bangkok 10330, Thailand

Tel +662188197

Email nutta.taneepanichskul@gmail.com 
specific population. A study of Tsunami disaster in 2004 of Thailand found that the prevalence of PTSD and PTSD symptoms among Thai survivors varied from $0.3 \%$ to $13 \%{ }^{12}$

The American Psychiatric Association stated that people with PTSD have symptoms including constant alertness, negative thoughts or nightmares. ${ }^{2}$ In addition, numerous studies have revealed an association between PTSD and sleep disturbance. ${ }^{13}$ Among Iraq and Afghanistan military veterans, PTSD was associated with a greater risk of obstructive sleep apnea (OSA). ${ }^{14}$ The possible mechanism is that traumatic events lead to a central stress response that increases the release of cortisol, which affects melatonin and reduces sleep quality. ${ }^{15}$ Firefighters are exposed to stressful situations which lead to the development of PTSD and effect on their sleep quality. Especially, firefighters who were working in the urban area may have chance to exposed and develop PTSD more than firefighters in rural area. Disaster prevention and mitigation plan revealed that Bangkok has the highest fire statistic since 2012-2016 in Thailand. ${ }^{16}$ Currently, little is known about PTSD and sleep quality among firefighters in the urban areas of Thailand; accordingly, a better understanding of the association between PTSD and sleep quality is needed. Therefore, the current study aimed to determine whether PTSD is associated with poor sleep quality among firefighters in Bangkok Thailand.

\section{Methods}

\section{Design and participants}

A cross-sectional study was conducted among firefighters from the 35 Fire Stations under the Fire Brigade Division of the Bangkok Fire and Rescue Department, which is a part of the Bangkok Metropolitan Administration (BMA). The inclusion criterion required the participants to have been actively working as a firefighter for at least one year, age more than or equal 18 years old and male firefighters. The total number of population in this study were 1702 professional firefighters; however, the eligible firefighters were 1569. Self-report questionnaires ( $\mathrm{N}=1569)$ were distributed to all eligible firefighters under the Bangkok Metropolitan Administration (BMA) which has the firefighters who were working in the area that have the highest fire statistic since 2012-2016 in Thailand. ${ }^{16}$ A total of 1215 questionnaires were returned, constituting a response rate of $77.44 \%$. The data collection period was April-July 2017. The study protocol was approved by the ethics review committee for research involving human research subjects, Health Science Group, Chulalongkorn University (COA No.
047.1/60). Participants were provided with information on the objectives and study design and written informed consents were obtained prior to participation. This study was conducted in accordance with the Declaration of Helsinki.

\section{Measurement tools}

\section{Posttraumatic Stress Disorder Checklist - Civilian Version}

The latest Thai edition of the PCL-C-THAI was utilized for identifying PTSD among firefighters in this study. A selfrated questionnaire consisting of 17 items associated with stressful experiences from traumatic events during the last month was distributed. Scoring of the answers is based on a 1 to 5 scale for each item. The PCL-C-THAI had good internal consistency (Cronbach's alpha $=0.96$ ) and a content validity of $0.77 .{ }^{17}$ Total scores of the 17 items ranged from 17 to 85 , and based on the previous literature, PTSD was classified into a dichotomous variable using 44 as the cut-off point. ${ }^{18}$ Firefighters with a score of less than or equal to 44 were identified as non-PTSD, while those with scores higher than 44 were classified as having a risk of developing PTSD. It should be noted that the cut-off point showed a sensitivity of 0.85 and a specificity of $0.73 .{ }^{19}$

\section{Pittsburgh Sleep Quality Index}

The Pittsburgh Sleep Quality Index Thai version (PSQITHAI) was utilized to access the sleep quality of firefighters during the past month. The self-report questionnaire consisted of 7 components and each item is weighted on a 0-3 interval scale, including subjective sleep quality, sleep latency, sleep duration, habitual sleep efficiency, sleep disturbances, use of sleep medication and daytime dysfunction due to sleep. The total score of the 7 components ranged from 0 to 21, with greater scores indicating poorer sleep quality. Based on the global PSQI score, firefighters with a score greater than 5 were classified as "poor sleepers", while those with scores less than or equal to 5 were classified as "good sleepers" ${ }^{20}$ The PSQITHAI was tested for internal consistency (Cronbach's alpha $=0.84$ ) and test-retest reliability (intraclass correlation coefficient $=0.89$ ), both of which were satisfactory. ${ }^{21}$ Meanwhile, sub-components of the PSQI ranged from 0 to 3.

\section{Covariate variables}

The questionnaire also included items related to sociodemographic factors, alcohol consumption, smoking, work history and depression. Sociodemographic factors included age (years), education level (Secondary or Vocational-High Certificate/Bachelor's Degree/Master's Degree or higher) 
and marital status (Single/Married and Living Together/ Widow). Alcohol consumption was initially classified into drinker and non-drinker with timeline follow-back periods of 7 days, defined 1 drink as equal to alcohol of $10 \mathrm{~g}$ according to Thai drinking survey guild, ${ }^{22}$ after which drinker was classified into 3 groups: drinking less than 3 times per week; drinking more than or equal to 3 times per week; and only on special occasions. For the smoking factor, participants were classified into current smoker and non-current smoker. Regarding health, physical activity was identified as exercising at least 20 mins per time (average from WHO recommendation, 150 mins per week $)^{23}$ and reported as either "yes" or "no". Body mass index (BMI) was calculated by weight $(\mathrm{kg}) /$ height $(\mathrm{m})^{2}$ and was classified into Underweight $\left(<18.5 \mathrm{~kg} / \mathrm{m}^{2}\right)$, Normal $\left(18.5-22.9 \mathrm{~kg} / \mathrm{m}^{2}\right)$ and Overweight ( $\geq 23.0 \mathrm{~kg} / \mathrm{m}^{2}$ ). For work history, the firefighters were asked to report their years of work as a firefighter. They were also asked to report whether they were involved in a major fire in Thailand, which was identified as either "Yes" or "No". Major fires were classified by consequence; that is, the potential for property and environmental damage/endangering the safety of personnel involved in the fire incident. In addition, firefighters were asked to report their history of occupational injuries (yes/no). Depression during the past 2 weeks was assessed by the Patient Health Questionnaire Depression Scale (PHQ-9) Thai version, for which the total score ranged from 0 to 27. Participants were classified as either having depression (score $\geq 10$ ) or not (score $<10$ ) based on a previous study. ${ }^{24}$

\section{Statistical analysis}

The statistical analysis was performed using SPSS version 22 software Chulalongkorn University licenses. The general demographics were described by means ( \pm standard deviation; SD) and medians (interquartile range; IQR) for continuous data and by counts and percentages (\%) for the categorical data. For the bivariate analysis, the Chi-square test was used for the categorical data; if the assumption was not met, Fisher's exact test was utilized. For the continuous data, Student's independent sample $t$-tests were applied; if the data were skewed, the MannWhitney $\mathrm{U}$ test was used. For the multivariate analysis, logistic regression was modeled to identify the association of PTSD status (non-PTSD vs PTSD) as an exposure with sleep quality (good sleep vs poor sleep) as outcomes among Bangkok firefighters. Unadjusted and multivariable adjusted logistic regression models were fit to estimate odds ratio and $95 \%$ confidence intervals $(95 \% \mathrm{CI})$ for the association between PTSD with sleep quality. Multivariate models were adjusted for covariate factors of sleep quality. We considered within station member as a random effect. All $p$-values are two-sided and defined as significant at the $5 \%$ level.

\section{Results}

\section{General information}

General information of the active male firefighters in Bangkok is presented in Table 1. The median age (IQR) for those with and without PTSD was 39.5 (35.8-43.3) and 39.0 (36.0-44.0) years, respectively. Results showed that $61.9 \%$ of non-PTSD firefighters and $48.7 \%$ of firefighters with PTSD had a bachelor's degree or higher. Accordingly, education showed a significant association with PTSD $(p=0.021)$. More than $60 \%$ of PTSD and non-PTSD firefighters were married and living together married/partners. In addition, non-PTSD firefighters exercised more regularly than those with PTSD. The median BMI (IQR) of firefighters with PTSD was higher than those without. Furthermore, the PTSD firefighters had a higher rate of drinking alcohol and smoking than did those without PTSD. It was noted that smoking was associated with PTSD. With respect to occupational factors, the duration of work and previous exposure to a major fire in Thailand were associated with PTSD. More specifically, $80.8 \%$ of firefighters with PTSD had experienced a major fire in Thailand. However, history of occupational injury did not present any association with PTSD. The depression (PHQ-9) score among PTSD and non-PTSD firefighters was significantly different. The median score (IQR) of the PHQ-9 for firefighters with PTSD was 9.0 (7.0-13.0) while for those without it was $2.0(0.0-5.0)$. The interesting point was that tobacco use, duration of work, experienced a major fire and depression were the risk factors significantly associated with PTSD.

\section{Prevalence of PTSD}

Of the 1215 firefighters, 78 firefighters (6.4\%) were categorized into the PTSD group using their PCL-C scores $(>44)$. The median score (IQR) of PTSD for the Bangkok firefighters was 22.0 (18.0-29.0). After classifying the firefighters into PTSD and non-PTSD groups, the median scores (IQR) were $45.0(45.0-51.0)$ and 22.0 (18.0-27.0), respectively.

\section{Prevalence of sleep quality}

Sleep quality and its components are reported in Tables 2 and 3. According to the PSQI score, $88.5 \%$ of firefighters 
Table I Prevalence of PTSD and general information among firefighters

\begin{tabular}{|c|c|c|c|c|c|}
\hline \multirow[t]{3}{*}{ General information } & \multicolumn{4}{|c|}{ PTSD (N = 1215$)$} & \multirow[t]{3}{*}{$p$-value } \\
\hline & \multicolumn{2}{|c|}{ Yes $(n=78 ; 6.4 \%)$} & \multicolumn{2}{|c|}{ No (n =II37; 93.6\%) } & \\
\hline & $\mathbf{n}$ & $\%$ & $\mathbf{n}$ & $\%$ & \\
\hline Age (median (IQR); years) & \multicolumn{2}{|c|}{$39.5(35.8-43.3)$} & \multicolumn{2}{|c|}{$39.0(36.0-44.0)$} & $0.653^{\mathrm{b}}$ \\
\hline Education level & & & & & $0.021^{\mathrm{a} *}$ \\
\hline Secondary/Vocational-High Certificate & 40 & 51.3 & 433 & 38.1 & \\
\hline Bachelor's Degree or higher & 38 & 48.7 & 704 & 61.9 & \\
\hline Marital status & & & & & $0.590^{\mathrm{a}}$ \\
\hline Single/Widow & 30 & 38.5 & 403 & 35.4 & \\
\hline Married/Living Together & 48 & 61.5 & 734 & 64.6 & \\
\hline Regular exercise, n (\%) & & & & & $0.053^{\mathrm{a}}$ \\
\hline Yes & 54 & 69.2 & 894 & 78.6 & \\
\hline No & 24 & 30.8 & 243 & 21.4 & \\
\hline Body mass index $\left(\mathrm{kg} / \mathrm{m}^{2}\right)$, mean (SD) & \multicolumn{2}{|c|}{$24.06(3.30)$} & \multicolumn{2}{|c|}{$23.83(3.56)$} & $0.554^{c}$ \\
\hline Alcohol consumption, n (\%) & & & & & $0.682^{\mathrm{a}}$ \\
\hline Yes & 60 & 76.9 & 851 & 74.8 & \\
\hline No & 18 & 23.1 & 286 & 25.2 & \\
\hline Smoker, n (\%) & & & & & $0.003^{\mathrm{a} *}$ \\
\hline Yes & 34 & 43.6 & 314 & 27.6 & \\
\hline No & 44 & 56.4 & 823 & 72.4 & \\
\hline Duration of work (years), median (IQR) & \multicolumn{2}{|c|}{$13.00(8.75-13.00)$} & \multicolumn{2}{|c|}{$10.00(8.00-13.00)$} & $0.00 I^{b^{*}}$ \\
\hline Exposure to major fire in Thailand, $\mathrm{n}$ (\%) & & & & & $0.024^{\mathrm{a}^{*}}$ \\
\hline Yes & 63 & 80.8 & 780 & 68.6 & \\
\hline No & 15 & 19.2 & 357 & 31.4 & \\
\hline Occupational injury, n (\%) & & & & & $0.409^{\mathrm{a}}$ \\
\hline Yes & 34 & 43.6 & 442 & 38.9 & \\
\hline No & 44 & 56.4 & 695 & 61.1 & \\
\hline Depression (PHQ-9) (median (IQR)) & \multicolumn{2}{|c|}{$9.00(7.00-13.00)$} & \multicolumn{2}{|c|}{$2.00(0.00-5.00)$} & $<0.001^{b^{b}}$ \\
\hline
\end{tabular}

Notes: *Significant at a $p$-value $<0.05$. aChi-square, ${ }^{b}$ Mann-Whitney $U$ test, ${ }^{c}$ Independent $t$-test.

Abbreviations: IQR, interquartile range; PHQ, Patient Health Questionnaire.

with PTSD, compared with only $46.4 \%$ without PTSD, reported poor sleep quality (PSQI score $>5$ ). All 7 components of the PSQI questionnaire were associated with PTSD status among firefighters.

\section{Posttraumatic stress disorder and sleep quality}

The PCL-C and PSQI scores among firefighters with PTSD were greater than for those without. The terms of sleep quality in each component were associated with PTSD. Component 1:
Subjective sleep quality $(p=0.001)$; Component 2: Sleep latency $(p<0.001)$; Component 3: Sleep duration $(p=0.003)$; Component 4: Sleep efficiency $(p<0.001)$; Component 5: Sleep disturbances $(p<0.001)$; Component 6: Use of sleep medication $(p<0.001)$; Component 7: Day-time dysfunction due to sleep $(p<0.001)$; and Overall sleep quality (Global PSQI Scores) $(p<0.001)$ (Table 2).

In the multivariate analysis, firefighters with PTSD were 4.36 times $(95 \% \mathrm{CI}: 1.54-12.37)$ more likely to have poorer sleep than non-PTSD-firefighters after 
Table 2 The comparison of Pittsburgh Sleep Quality index between the firefighters with and without PTSD

\begin{tabular}{|c|c|c|c|c|c|}
\hline \multirow[t]{3}{*}{ Sleep quality components } & \multicolumn{4}{|c|}{ PTSD (N = 1215$)$} & \multirow[t]{3}{*}{$p$-value } \\
\hline & \multicolumn{2}{|c|}{ Yes (n =78; 6.4\%) } & \multicolumn{2}{|c|}{ No $(n=I 137 ; 93.6 \%)$} & \\
\hline & $\mathbf{n}$ & $\%$ & $\mathbf{n}$ & $\%$ & \\
\hline Subjective sleep quality & & & & & $0.001 *$ \\
\hline Very good & 16 & 20.5 & 323 & 28.4 & \\
\hline Fairly good & 39 & 50.0 & 649 & 57.1 & \\
\hline Fairly bad & 18 & 23.1 & 146 & 12.8 & \\
\hline Very bad & 5 & 6.4 & 19 & 1.7 & \\
\hline Sleep latency (mins) & & & & & $<0.001 *$ \\
\hline$\leq 15$ & 3 & 3.8 & 393 & 34.6 & \\
\hline $16-30$ & 16 & 20.5 & 232 & 20.4 & \\
\hline $31-60$ & 58 & 74.4 & 503 & 44.2 & \\
\hline$>60$ & 1 & 1.3 & 9 & 0.8 & \\
\hline Sleep duration (hrs) & & & & & $0.003 *$ \\
\hline$\leq 5.0$ & 37 & 47.4 & 355 & 31.2 & \\
\hline $5.1-6.0$ & 26 & 33.3 & 338 & 29.7 & \\
\hline $6.1-7.0$ & 7 & 9.0 & 251 & 22.1 & \\
\hline$>7.0$ & 8 & 10.3 & 193 & 17.0 & \\
\hline Sleep efficiency & & & & & $<0.00$ I* \\
\hline$<65 \%$ & 25 & 32.1 & 190 & 16.7 & \\
\hline $65-74 \%$ & 18 & 23.1 & 155 & 13.6 & \\
\hline $75-85 \%$ & 24 & 30.8 & 291 & 25.6 & \\
\hline$>85 \%$ & $\mathrm{II}$ & 14.1 & 501 & 44.1 & \\
\hline Sleep disturbances & & & & & $<0.001 *$ \\
\hline Not during the past month & 1 & 1.3 & 80 & 7.0 & \\
\hline Less than once a week & 25 & 32.1 & 764 & 67.2 & \\
\hline Once or twice a week & 48 & 61.5 & 285 & 25.1 & \\
\hline Three or more times a week & 4 & 5.1 & 8 & 0.7 & \\
\hline Use of sleep medication & & & & & $<0.00$ I* \\
\hline Never & 48 & 61.5 & 1,059 & 93.1 & \\
\hline Ever & 30 & 38.5 & 78 & 6.9 & \\
\hline Daytime dysfunction due to sleep & & & & & $<0.001 *$ \\
\hline Never & 9 & 11.5 & 407 & 35.8 & \\
\hline$\leq 2$ times a week & 67 & 85.9 & 726 & 63.9 & \\
\hline$>2$ times a week & 2 & 2.6 & 4 & 0.4 & \\
\hline Overall sleep quality (Global PSQI Scores) & & & & & $<0.001 *$ \\
\hline Good Sleep (PSQI $\leq 5$ ) & 9 & 11.5 & 610 & 53.6 & \\
\hline Poor sleep (PSQI > 5) & 69 & 88.5 & 527 & 46.4 & \\
\hline
\end{tabular}

Note: $*$ Significant at a $p$-value $<0.05$ for Chi-square Test.

Abbreviations: PSQI, Pittsburgh Sleep Quality Index, PTSD, posttraumatic stress disorder.

adjusted for age, smoke, alcohol consumption, caffeine, 2.99 fold increase odds of longer sleep latency (95\% CI: duration of work and depression. PTSD-firefighters had 1.12-7.96), 7.74 fold increase odds of poor sleep 


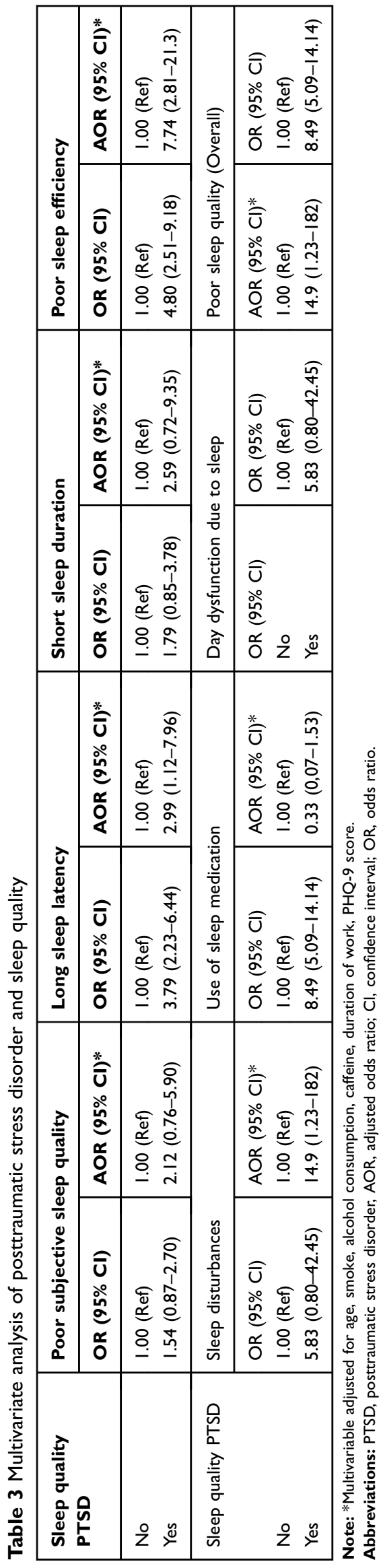

efficiency (95\% CI 2.81-21.4), 0.33 fold increase odds of use of sleep medication ( $95 \%$ CI $0.07-1.53$ ) and 4.35 fold increase odds of daytime dysfunction (95\% CI: 1.43-13.2) than non-PTSD-firefighters (Table 3).

\section{Discussion}

As anticipated, results of current study indicated a significant association between PTSD and sleep quality among firefighters in Bangkok, Thailand. The prevalence of PTSD among firefighters (PCL scores $>44$ ) was 6.4\%, and of those, more than $80 \%$ had poor sleep quality. Accordingly, PTSD status apparently constitutes an increased risk of poor sleep quality among urban firefighters in Thailand. These results can be generalized to firefighters in an urban area in other countries. Comparing the prevalence of PTSD among firefighters from other countries, we found that percentage of urban firefighters in Thailand suffering from PSTD was less than for Japanese firefighters (between $9.4 \%$ and $21.9 \%$ ), ${ }^{25}$ German firefighters $(18.2 \%)^{26}$ and Saudi firefighters $(57 \%) .{ }^{27}$ As mentioned, the current study found that smoking was associated with PTSD. This finding is similar to Kearns et al's finding, ${ }^{28}$ who indicated that individuals with PTSD were approximately twice as likely to be current smokers and the study of VanderVeen et al $(2012)^{29}$ found that smoking relapse was associated with occupational stress among firefighters in North America. With respect to occupational characteristics, our study showed that the duration of work was associated with PTSD, while occupational injuries were not associated with PTSD, which is inconsistent with Katsavouni et al; ${ }^{30}$ their study suggested that work-related injuries (WRIs) were associated with PTSD among Greek firefighters. We found that experiencing a major fire in Thailand was associated with PTSD. This finding is similar to the results by Soo et $\mathrm{al}^{31}$ who suggested that firefighters who arrived early at the World Trade Center in September 2001 had a higher chance of developing PTSD. Saijo, Ueno, \& Hashimoto (2012), ${ }^{25}$ revealed that PTSD was associated with depression among firefighters of urban Japan, which echoes the results in this study.

The prevalence of urban firefighters in Thailand with poor sleep quality was $49.1 \%$. Compared to other countries, the prevalence of sleep disorders among South Korean male firefighters was $48.7 \%,{ }^{32}$ while $69.9 \%$ of Tehran fire and rescue service members in Iran reported poor sleep. ${ }^{33}$ Accordingly, the current results revealed an association between PTSD and sleep disturbance among 
urban firefighters in Thailand. These results are consistent with Khazaie et al, (2016) ${ }^{13}$ who studied veterans with chronic-war-induced PTSD and among patients with PTSD. ${ }^{34}$ Several reasons could support our findings. According to the Diagnostic and Statistical Manual of Mental Disorders, Fifth Edition (DSM-5), it is suggested that hyperarousal and reactivity in the diagnosis of PTSD induced sleep problems in patients, especially difficulty in falling asleep and nightmares. ${ }^{3}$ PTSD symptoms include alertness, negative thoughts or nightmares, all of which contribute to poor sleep quality.

Several limitations in our study must be mentioned. First, sleep quality of firefighter in our study was not differentiate between on-duty and off-duty because the timeframe of PSQI is 30 days. Therefore, we cannot differentiate between on- and off-duty sleep quality among these firefighters. Further study should investigate the sleep quality of firefighter during on-duty and off-duty. Second, call volume during the evening and night hours and shift work schedule were not considered in our analysis because of underreport of call volume and non-standard shift-work pattern. The work pattern among Bangkok firefighters is 24 hrs on duty for 3-4 days per week. The schedule depended on fire station.

Second, a cross-sectional study cannot conclude a causal relationship between PTSD and sleep problems. Third, PTSD and the sleep quality of firefighters were assessed by self-report questionnaire, which leads to information bias. Fourth, our different cut-off point of the PCL-C questionnaire for PTSD prediction may have led to an overestimated prevalence; specifically, our study considered the cut-point criteria for civilians (scores $>44$ ), which may be different from other studies. Lastly, our results cannot be generalized to wildfire firefighters in Thailand because of the different characteristics of the fire.

In conclusion, $6.4 \%$ of current Bangkok firefighters reported PTSD with the PCL cut-point criteria for civilians. Firefighters with PTSD had a significantly increased prevalence of poor sleep quality compared to those without. Accordingly, our results suggest that interventions and a policy related to the psychological well-being among firefighters in Thailand are needed to enhance their health.

\section{Acknowledgments}

We would like to thank all Bangkok firefighters and the Bangkok Fire and Rescue Department and the Bangkok Metropolitan Administration (BMA). This study was funded by the 90th Anniversary of Chulalongkorn
University Fund (Ratchadaphiseksomphot Endowment Fund), Office of Higher Education Commission and the Thailand Research Fund (TRF). This study was presented at the 2017 Kyoto Global Conference for Rising Public Health Researchers (KGC).

\section{Disclosure}

The authors declare no conflicts of interest in this work.

\section{References}

1. Reh BD, Weber J. A summary of health hazard evaluations; issues related to occupational exposure to fire fighters, 1990 to 2001. The National Institute for Occupational Safety and Health (NIOSH) No. 2004-116; Avaliable from: https://stacks.cdc.gov/view/cdc/6564. Accessed July 9, 2019

2. Association AP. Diagnostic and Statistical Manual of Mental Disorders (DSM-5®). Washington (DC): American Psychiatric Pub; 2013.

3. U.S. Department of veterans affairs. PTSD and DSM-5; 2017. Available from: https://www.ptsd.va.gov/professional/PTSD-over view/dsm5_criteria_ptsd.asp. Accessed July 9, 2019.

4. Coughlin SS. Post-traumatic stress disorder and cardiovascular disease. Open Cardiovasc Med J. 2011;5:164. doi:10.2174/ 1874192401105010164

5. Usui C, Hatta K, Aratani S, et al. Vulnerability to traumatic stress in fibromyalgia patients: 19 month follow-up after the great East Japan disaster. Arthritis Res Ther. 2013;15(5):R130. doi:10.1186/ar4310

6. Cougle JR, Resnick H, Kilpatrick DG. PTSD, depression, and their comorbidity in relation to suicidality: cross-sectional and prospective analyses of a national probability sample of women. Depress Anxiety. 2009;26(12):1151-1157. doi:10.1002/da.20621

7. Westermeyer J, Khawaja IS, Freerks M, et al. Quality of sleep in patients with posttraumatic stress disorder. Psychiatry (Edgmont). 2010;7(9):21.

8. Ferry F, Bunting B, Murphy S, O’Neill S, Stein D, Koenen K. Traumatic events and their relative PTSD burden in Northern Ireland: a consideration of the impact of the 'Troubles'. Soc Psychiatry Psychiatr Epidemiol. 2014;49(3):435-446. doi:10.1007/ s00127-013-0757-0

9. Atwoli L, Stein DJ, Williams DR, et al. Trauma and posttraumatic stress disorder in South Africa: analysis from the South African Stress and Health Study. BMC Psychiatry. 2013;13(1):182. doi:10.1186/1471-244X-13-182

10. Berninger A, Webber MP, Niles JK, et al. Longitudinal study of probable post-traumatic stress disorder in firefighters exposed to the World Trade Center disaster. Am J Ind Med. 2010;53(12):1177-1185. doi:10.1002/ajim.20894

11. Chiu S, Webber MP, Zeig-Owens R, et al. Performance characteristics of the PTSD checklist in retired firefighters exposed to the World Trade Center disaster. Ann Clin Psychiatry. 2011;23(2):95-104.

12. Udomratn P. Prevalence of tsunami-related PTSD and MDD in Thailand. Asian J Psychiatr. 2009;2(4):124-127. doi:10.1016/j. ajp.2009.10.008

13. Khazaie H, Ghadami MR, Masoudi M. Sleep disturbances in veterans with chronic war-induced PTSD. J Inj Violence Res. 2016;8(2):99.

14. Colvonen PJ, Masino T, Drummond SP, Myers US, Angkaw AC, Norman SB. Obstructive sleep apnea and posttraumatic stress disorder among OEF/OIF/OND veterans. J Clin Sleep Med. 2015;11(5):513.

15. Otte C, Lenoci M, Metzler T, Yehuda R, Marmar CR, Neylan TC. Hypothalamic-pituitary-adrenal axis activity and sleep in posttraumatic stress disorder. Neuropsychopharmacology. 2005;30(6):11731180. doi: $10.1038 /$ sj.npp. 1300676 
16. The Bangkok Fire and Rescue Department. Bangkok fire prevention and mitigation plan 2018. Bangkok (Thailand): The Bangkok Metropolitan Administration; 2018.

17. Chawanakrasaesin P, Rukskul I, Ratanawilai A. Validity and reliability of Thai version of the posttraumatic stress disorder checklist. $J$ Psychiatric Assoc Thailand. 2011;56:4.

18. National Center for PTSD. Using the PTSD checklist (PCL). US Department of Veterans Affairs; 2012. Available from: https://sph.umd. edu/sites/default/files/files/PTSDChecklistScoring.pdf. Accessed July 9, 2019.

19. Terhakopian A, Sinaii N, Engel CC, Schnurr PP, Hoge CW. Estimating population prevalence of posttraumatic stress disorder: an example using the PTSD checklist. J Trauma Stress. 2008;21 (3):290-300. doi:10.1002/jts.20341

20. Buysse DJ, Reynolds CF, Monk TH, Berman SR, Kupfer DJ. The Pittsburgh Sleep Quality Index: a new instrument for psychiatric practice and research. Psychiatry Res. 1989;28(2):193-213.

21. Sitasuwan T, Bussaratid S, Ruttanaumpawan P, Chotinaiwattarakul W. Reliability and validity of the Thai version of the Pittsburgh Sleep Quality Index. J Med Assoc Thai. 2014;97(Suppl 3):S57-S67.

22. Research Institute for Health Sciences. Thai Drinking Survey Guild. Chiang Mai (Thailand): Chiang Mai University; 2010.

23. World Health Organization. Global Recommendations on Physical Activity for Health. Geneva (Switzerland): WHO Press; 2010.

24. Lotrakul M, Sumrithe S, Saipanish R. Reliability and validity of the Thai version of the PHQ-9. BMC Psychiatry. 2008;8(1):46. doi: $10.1186 / 1471-244 X-8-46$

25. Saijo Y, Ueno T, Hashimoto Y. Post-traumatic stress disorder and job stress among firefighters of urban Japan. Prehosp Disaster Med. 2012;27(1):59-63. doi:10.1017/S1049023X12000222
26. Wagner D, Heinrichs M, Ehlert U. Prevalence of symptoms of posttraumatic stress disorder in German professional firefighters. Am J Psychiatry. 1998;155(12):1727-1732. doi:10.1176/ajp.155.12.1727

27. Alghamd M, Hunt N, Thomas S. Prevalence rate of post-traumatic stress disorders (PTSD) and other psychological disorders among Saudi firefighters. Eur J Psychotraumatol. 2013;4. doi:10.3402/ejpt. v4i0.22652

28. Kearns NT, Carl E, Stein AT, et al. Posttraumatic stress disorder and cigarette smoking: a systematic review. Depress Anxiety. 2018;35 (11):1056-1072. doi:10.1002/da.22828

29. VanderVeen JW, Gulliver SB, Morissette SB, et al. Differences in drinking patterns, occupational stress, and exposure to potentially traumatic events among firefighters: predictors of smoking relapse. Am J Addict. 2012;21(6):550-554. doi:10.1111/j.15210391.2012.00282.x

30. Katsavouni F, Bebetsos E, Malliou P, Beneka A. The relationship between burnout, PTSD symptoms and injuries in firefighters. Occup Med (Chic Ill). 2015;66(1):32-37. doi:10.1093/occmed/kqv144

31. Soo J, Webber MP, Gustave J, et al. Trends in probable PTSD in firefighters exposed to the World Trade Center disaster, 2001-2010. Disaster Med Public Health Prep. 2011;5(S2):S197-S203. doi:10.1001/dmp.2011.48

32. Lim D-K, Baek K-O, Chung I-S, Lee M-Y. Factors related to sleep disorders among male firefighters. Ann Occup Environ Med. 2014;26 (1):11. doi:10.1186/2052-4374-26-11

33. Mehrdad R, Haghighi KS, Esfahani AHN. Sleep quality of professional firefighters. Int J Prev Med. 2013;4(9):1095.

34. Leskin GA, Woodward SH, Young HE, Sheikh JI. Effects of comorbid diagnoses on sleep disturbance in PTSD. J Psychiatr Res. 2002;36(6):449-452.
Nature and Science of Sleep

\section{Publish your work in this journal}

Nature and Science of Sleep is an international, peer-reviewed, open access journal covering all aspects of sleep science and sleep medicine, including the neurophysiology and functions of sleep, the genetics of sleep, sleep and society, biological rhythms, dreaming, sleep disorders and therapy, and strategies to optimize healthy sleep.
The manuscript management system is completely online and includes a very quick and fair peer-review system, which is all easy to use. Visit http://www.dovepress.com/testimonials.php to read real quotes from published authors. 